\title{
Tyrosine Kinase Inhibitors in EGFR- Mutated Large-Cell Neuroendocrine Carcinoma of the Lung? A Case Report
}

\author{
Francesca Aroldi $^{\mathrm{a}} \quad$ Paola Bertocchi ${ }^{\mathrm{a}} \quad$ Fausto Meriggi $^{\mathrm{a}} \quad$ Chiara Abeni $^{\mathrm{a}}$ \\ Chiara Ogliosi $^{a}$ Luigina Rota ${ }^{a}$ Claudia Zambelli ${ }^{b}$ Claudio Bnàc \\ Alberto Zaniboni ${ }^{a}$ \\ ${ }^{a}$ Oncology Department, ${ }^{b}$ Pathologic Anatomy Department and ' Radiology Department, \\ Poliambulanza Foundation, Brescia, Italy
}

\section{Key Words}

Large-cell neuroendocrine carcinoma - Epidermal growth factor receptor mutation - Tyrosine kinase inhibitors · Gefitinib

\begin{abstract}
Large-cell neuroendocrine carcinoma (LCNEC) of the lung is a high-grade carcinoma belonging to the neuroendocrine tumors of the lung and is different from typical lung large-cell carcinoma. It represents about $3 \%$ of all pulmonary malignancies and is characterized by neuroendocrine cytologic features. The treatment usually is platinum-based chemotherapy, however the outcome remains poor. Therefore new therapeutic options are needed. Tyrosine kinase inhibitors have demonstrated greater efficacy and better tolerability than standard chemotherapy in non-small-cell lung cancer harboring epidermal growth factor receptor (EGFR) mutations. EGFR gene mutations were also rarely identified in LCNEC. We report a patient with lung LCNEC activating EGFR mutations who showed an impressive response to gefitinib.

(c) 2014 S. Karger AG, Basel
\end{abstract}

\section{Introduction}

During the last years tyrosine kinase inhibitors (TKIs) have changed the natural history of metastatic non-small-cell lung cancer (NSCLC) harboring epidermal growth factor receptor (EGFR) mutations. Eight important studies were conducted to evaluate the efficacy 
Aroldi et al.: Tyrosine Kinase Inhibitors in EGFR-Mutated Large-Cell Neuroendocrine Carcinoma of the Lung? A Case Report

and tolerability of TKIs on advanced NSCLC in comparison with standard platinum-based chemotherapy [1]. Not surprisingly, the use of TKIs was correlated with a higher response rate, a longer progression-free survival and a better quality of life in patients with advanced NSCLC activating EGFR mutation. The IRESSA Pan-Asia Study (IPASS), which enrolled 1,217 patients, was the largest trial in which patients were randomized to receive gefitinib or standard chemotherapy, and in the group of TKIs therapy the primary endpoints were reached obtaining a statistically significantly higher response rate, a longer progression-free survival and better symptom control [1]. Similar results were reported by First-SIGNAL and by West Japan Thoracic Oncology Group (WJTOG 3405) studies [1]. The North-East Japan Study group (NEJ002) trial was stopped early because gefitinib showed a significantly higher progression-free survival in comparison with standard chemotherapy in patients with advanced lung adenocarcinoma activating EGFR mutation [1]. Impressive results were also reported with the use of other TKIs such as erlotinib or afatinib versus chemotherapy in patients carrying the same EGFR mutations [1]. Better responses were observed in patients with mutations in exons 18-21 of the tyrosine kinase domain of EGFR [2]. However, EGFR gene mutations were also identified in small-cell lung cancer (SCLC) $[3,4]$ and in large-cell neuroendocrine carcinoma (LCNEC) of the lung. LCNEC is a high-grade carcinoma ( $>10$ mitoses $/ 2 \mathrm{~mm}^{2}$ ) belonging to the neuroendocrine tumors of the lung. It represents about $3 \%$ of all pulmonary malignancies and is characterized by neuroendocrine cytologic features (formation of rosettes, trabeculae and perilobular palisading pattern) and markers (neuronspecific enolase, CD56, synaptophysin, chromogranin and Leu7) [5]. In fact, the cytologic and biologic features of LCNEC are different from those of large-cell carcinoma [6]. The molecular alterations that are commonly found in LCNEC are p53, Bcl-2 overexpression and $\mathrm{Rb}$ mutation. To our knowledge, few cases of LCNEC with EGFR gene mutation have been described up to now, and only one case was treated with gefitinib, with a good response [7, 8].

\section{Case Presentation}

A 47-year-old Caucasian woman with no family history of neoplastic diseases and no comorbidities was examined by a general practitioner after the appearance of back pain unresponsive to usual non-steroidal anti-inflammatory drugs. Standard chest X-ray showed a left lung perihilar lesion, probably suggesting pneumonia. As a consequence, the patient started a broad-spectrum antibiotic therapy without resolution of her symptoms. Thus, after 2 weeks, chest X-ray was repeated and showed persistence and stability of the left lung lesion. About 1 month later, the patient came for the first time to our attention for appearance of vomiting, dyspnea, fatigue and abdominal pain (visual analog scale 7). Abdominal physical examination revealed a painful hepatomegaly. She underwent a total body computed tomography (CT) scan that showed multiple focal liver lesions, solid left lung tissue and multiple secondary brain lesions (two left frontal cerebral lesions, one right parietal lesion and two cerebellar lesions) (fig. 1). As a result, a liver biopsy was performed. Since all investigated tumor markers (carcinoembryonic antigen, carbohydrate antigen 19-9, carbohydrate antigen 125 , neuron-specific enolase, glycoprotein hormones alpha polypeptide) were increased, it was not possible to identify the primary site of localization of the tumor and to reach a definitive diagnosis. Given the rapidly progressive impairment of her clinical conditions and performance status, we administered an empirically not targeted chemotherapy with gemcitabine $1,000 \mathrm{mg} / \mathrm{m}^{2}$ die 1 and oxaliplatin $100 \mathrm{mg} / \mathrm{m}^{2}$ die $2 \mathrm{q} 2$ weeks although we did not yet have definitive histopathological results. About 1 week later, the 
Aroldi et al.: Tyrosine Kinase Inhibitors in EGFR-Mutated Large-Cell Neuroendocrine Carcinoma of the Lung? A Case Report

results were provided. Although the sample was poor, the diagnosis was evocative of lung adenocarcinoma (TTF-1 positive, cytokeratin 7 positive). However, since a further deterioration of her clinical condition was observed, a biopsy was repeated in order to have an additional sample for molecular analysis. This second histological report was diagnostic for LCNEC of the lung. Tumor cellularity showed focal TTF-1 and diffuse synaptophysin positivity (fig. 2). A molecular analysis was performed and showed an EGFR mutation (exon 19). Therefore, we started TKI therapy and gefitinib was administered at $250 \mathrm{mg}$ p.o. once a day. Ten days later the patient was getting better. She had no more symptoms such as dyspnea, fatigue, vomiting or pain. Abdominal physical examination was within normal range. Today the treatment is still ongoing. The patient reports a good quality of life and no relevant side effects (skin toxicity grade 1) have been registered. A restaging total body CT scan showed a significant improvement of disease, with a partial response $>50 \%$. Particularly, the brain CT scan showed a significantly reduced volume of the lesions (valuable only $2 / 5$ lesions) and complete resolution of edema (fig. 1). Up to date the progression-free survival is 5 months.

\section{Discussion}

LCNEC is a rare tumor which is usually treated with cisplatin-based chemotherapy as SCLC [9] as it shares many characteristics with it. Usually, the administration of TKIs is considered only for advanced lung adenocarcinoma because the most important studies demonstrating higher activity of TKI, in comparison with standard platinum-based chemotherapy, were conducted in patients affected by NSCLC with EGFR mutations. Some features are associated with a higher possibility that EGFR mutations are present in NSCLC [10]. The research of EGFR mutations is not performed routinely on LCNEC since this mutation is not commonly present in this subtype. The prognosis of this tumor with standard chemotherapy is poor [11], thus we need to evaluate alternative diagnostic strategies such as the investigation of EGFR mutational status in order to explore new effective treatments. We report the case of a patient affected by LCNEC carrying all of the predictive characteristics associated with EGFR mutation (Caucasian, female, never-smoker). When the patient came to our attention she was very symptomatic, so in an attempt to reach a better and faster response, we decided to test EGFR mutational status. Strikingly, the mutation was present, and we were allowed to administered gefitinib, obtaining an impressive and objective response. Therefore, we suggest the research of EGFR mutations also in patients with LCNEC to offer them one more therapeutic option.

\section{Disclosure Statement}

The authors have nothing to disclose. 
Aroldi et al.: Tyrosine Kinase Inhibitors in EGFR-Mutated Large-Cell Neuroendocrine Carcinoma of the Lung? A Case Report

\section{References}

1 Costanzo R, Montanino A, Di Maio M, Piccirillo MC, Sandomenico C, Giordano P, Daniele G, Franco R, Perrone F, Rocco G, Normanno N, Morabito A: Advanced non-small-cell lung cancer with epidermal growth factor receptor mutations: current evidence and future perspectives. Expert Rev Anticancer Ther 2013;13:12071218.

-2 Paez JG, Jänne PA, Lee JC, Tracy S, Greulich H, Gabriel S, Herman P, Kaye FJ, Lindeman N, Boggon TJ, Naoki K, Sasaki H, Fujii Y, Eck MJ, Sellers WR, Johnson BE, Meyerson M: EGFR mutations in lung cancer: correlation with clinical response to gefitinib therapy. Science 2004;304:1497-1500.

-3 Araki J, Okamoto I, Suto R, Ichikawa Y, Sasaki J: Efficacy of the tyrosine kinase inhibitor gefitinib in a patient with metastatic small cell lung cancer. Lung Cancer 2005;48:141-144.

4 Okamoto I, Araki J, Suto R, Shimada M, Nakagawa K, Fukuoka M: EGFR mutation in gefitinib-responsive small-cell lung cancer. Ann Oncol 2006;17:1028-1029.

-5 Hiroshima K, Iyoda A, Shida T, Shibuya K, Iizasa T, Kishi H, Tanizawa T, Fujisawa T, Nakatani Y: Distinction of pulmonary large cell neuroendocrine carcinoma from small cell lung carcinoma: a morphological, immunohistochemical, and molecular analysis. Mod Pathol 2006;19:1358-1368.

6 Iyoda A, Hiroshima K, Moriya Y, Mizobuchi T, Otsuji M, Sekine Y, Shibuya K, Iizasa T, Saitoh Y, Fujisawa T: Pulmonary large cell neuroendocrine carcinoma demonstrates high proliferative activity. Ann Thorac Surg 2004;77:1891-1895; discussion 1895.

7 Iyoda A, Makino T, Koezuka S, Otsuka H, Hata Y: Treatment options for patients with large cell neuroendocrine carcinoma of the lung. Gen Thorac Cardiovasc Surg 2014;62:351-356.

$\checkmark 8$ De Pas TM, Giovannini M, Manzotti M, Trifirò G, Toffalorio F, Catania C, Spaggiari L, Labianca R, Barberis M: Large-cell neuroendocrine carcinoma of the lung harboring EGFR mutation and responding to gefitinib. J Clin Oncol 2011;29:e819-e822.

-9 Yamazaki S, Sekine I, Matsuno Y, Takei H, Yamamoto N, Kunitoh H, Ohe Y, Tamura T, Kodama T, Asamura H, Tsuchiya R, Saijo N: Clinical responses of large cell neuroendocrine carcinoma of the lung to cisplatin-based chemotherapy. Lung Cancer 2005;49:217-223.

10 Chou TY, Chiu CH, Li LH, Hsiao CY, Tzen CY, Chang KT, Chen YM, Perng RP, Tsai SF, Tsai CM: Mutation in the tyrosine kinase domain of epidermal growth factor receptor is a predictive and prognostic factor for gefitinib treatment in patients with non-small cell lung cancer. Clin Cancer Res 2005;11:3750-3757.

11 Le Treut J, Sault MC, Lena H, Souquet PJ, Vergnenegre A, Le Caer H, Berard H, Boffa S, Monnet I, Damotte D, Chouaid C: Multicentre phase II study of cisplatin-etoposide chemotherapy for advanced large-cell neuroendocrine lung carcinoma: the GFPC 0302 study. Ann Oncol 2013;24:1548-1552. 
Case Rep Oncol 2014;7:478-483

DOI: $10.1159 / 000365413$

Aroldi et al.: Tyrosine Kinase Inhibitors in EGFR-Mutated Large-Cell Neuroendocrine Carcinoma of the Lung? A Case Report
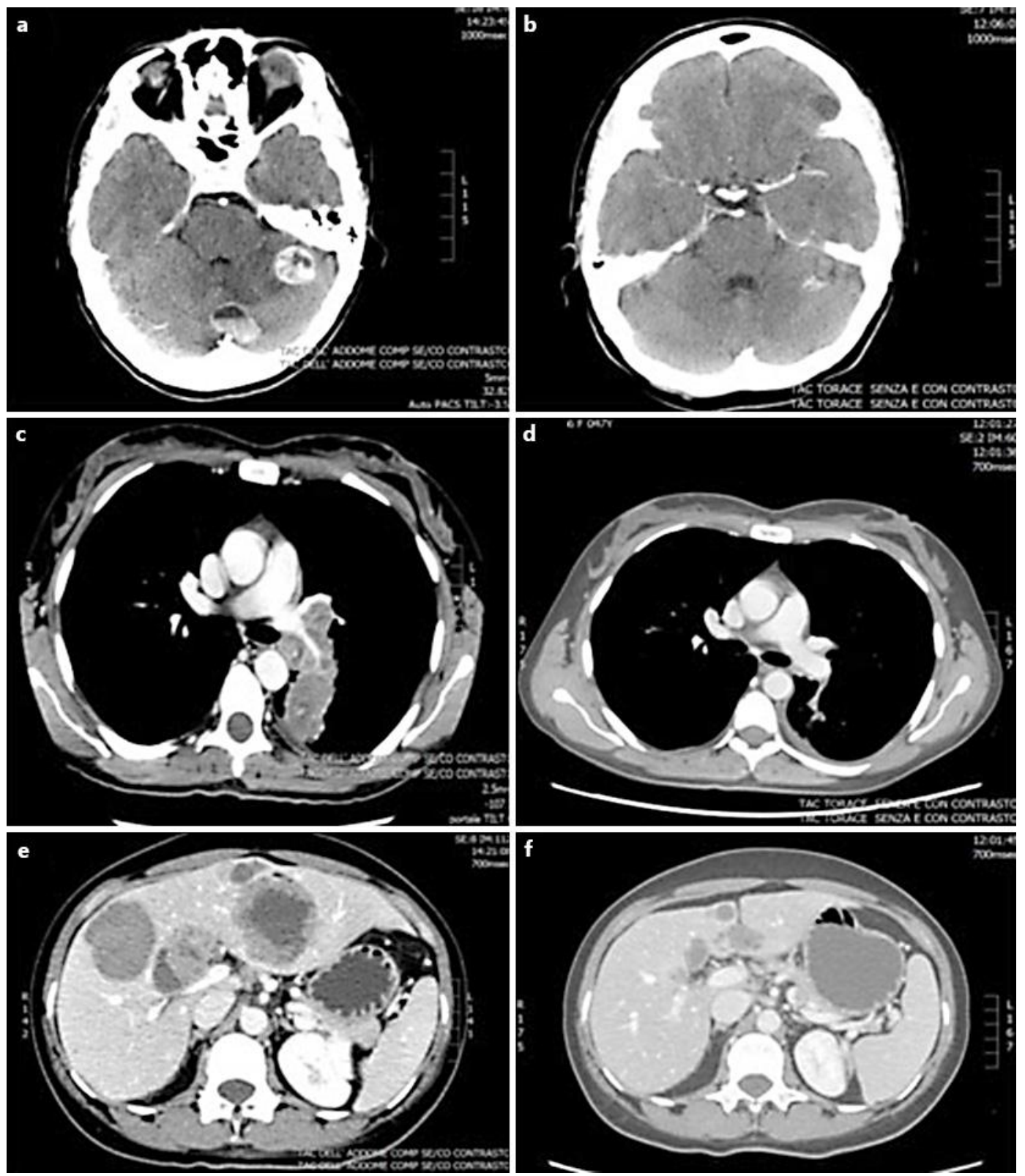

Fig. 1. CT imaging results. 
Aroldi et al.: Tyrosine Kinase Inhibitors in EGFR-Mutated Large-Cell Neuroendocrine Carcinoma of the Lung? A Case Report
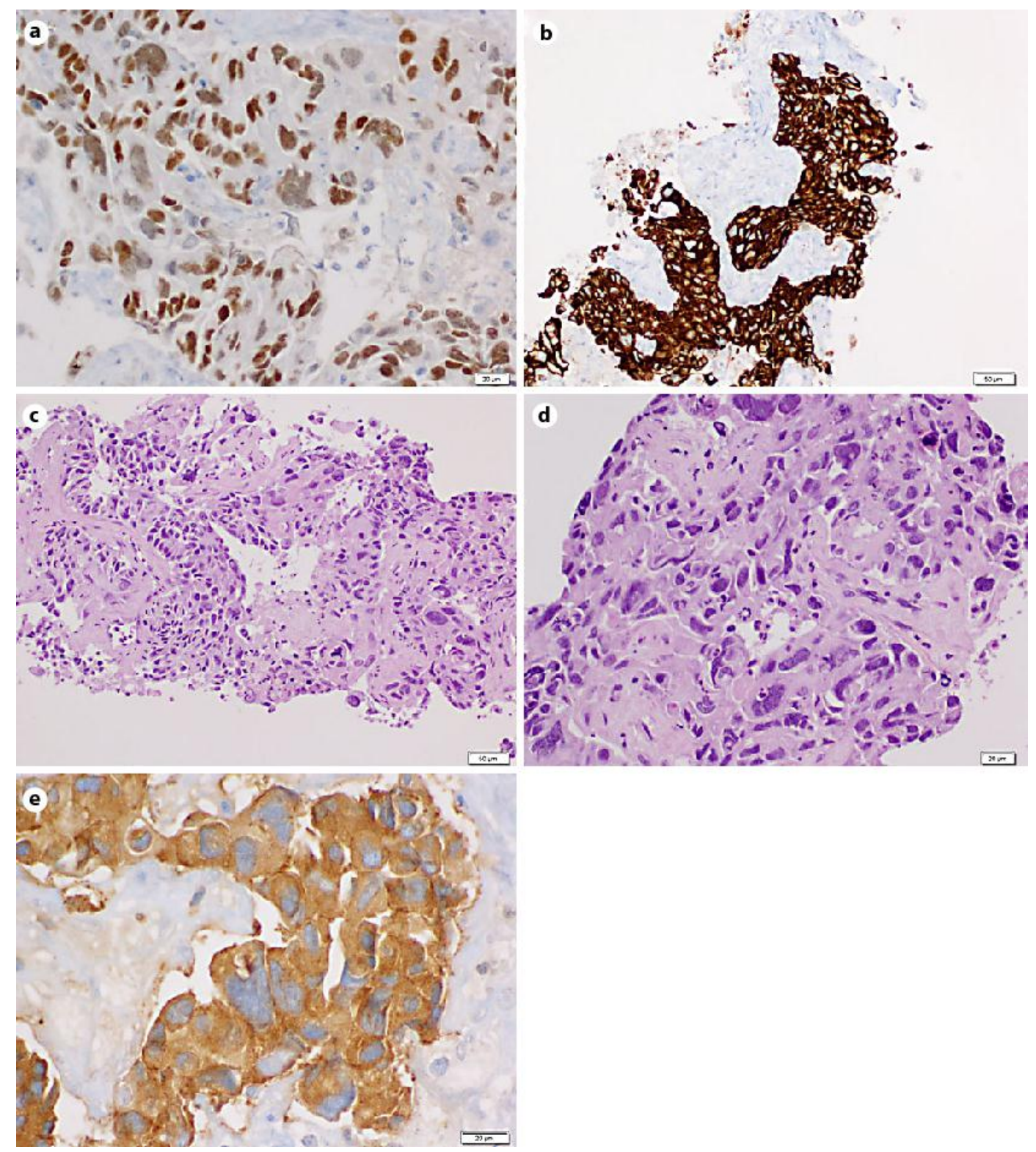

Fig. 2. Histological features. 